\title{
PESQUISA E(M) MOVIMENTO: SISTEMATIZANDO EXPERIÊNCIAS DE EDUCAÇÃO POPULAR
}

\author{
Resenha de: PAULO, Fernanda dos Santos. Memórias $e$ \\ trajetórias: sistematização de experiências de educação popular e \\ movimentos sociais. São Paulo: Diálogo Freireano, 2019.
}

\author{
DCarolina Schenatto da Rosa \\ Doutoranda em Educação, Universidade do Vale do Rio dos Sinos - Unisinos \\ São Leopoldo, Rio Grande do Sul, Brasil \\ carolinaschenatto@gmail.com \\ (iD) Diandra dos Santos de Andrade \\ Mestranda em Educação, Universidade do Vale do Rio dos Sinos - Unisinos \\ São Leopoldo, Rio Grande do Sul, Brasil \\ diandra.andrade@hotmail.com \\ (1) Thainá Cristina Guedes \\ Graduanda em Pedagogia, Universidade do Vale do Rio dos Sinos - Unisinos \\ São Leopoldo, Rio Grande do Sul, Brasil \\ thaai.guedes@hotmail.com
}

Para citar- (ABNT NBR 6023:2018)

ROSA, Carolina Schenatto da; ANDRADE, Diandra dos Santos de; GUEDES, Thainá Cristina. Pesquisa e(m) movimento: sistematizando experiências de educação popular. Resenha. Eccos - Revista Cientifica, São Paulo, n. 55, p. 1-5, e18522, out./dez., 2020. Resenha da obra de PAULO, Fernanda dos Santos. Memórias $e$ trajetórias: sistematização de experiências de educação popular e movimentos sociais. São Paulo: Diálogo Freireano, 2019. Disponível em: https://doi.org/10.5585/eccos.n55.18522.

A Sistematização de Experiências (SE) é muito mais do que uma estratégia de pesquisa, uma mera opção metodológica; é um exercício crítico e político-pedagógico intrinsecamente relacionado às formas de construir conhecimento coletiva e ativamente na América Latina por meio da relação entre Universidade e Educação Popular. Inserida no bojo da Pesquisa Participante, é uma "metodologia e instrumento que contribuirá para a construção e produção do conhecimento crítico-problematizador" (PAULO, 2019, p. 78).

Eticamente comprometida com a emancipação de todos e todas que se envolvem no processo, em sua dimensão metodológica, a SE relaciona-se com o movimento de conhecer e caminhar no entrelugar das nossas heranças (des)coloniais por meio do diálogo e da autorreflexão coletiva. É um exercício conjunto e direcionado de autoconhecimento, de partilha e escrita das trajetórias de movimentos coletivos e demais organizações de forma a, pedagogicamente, identificar e compreender, nas próprias práticas, ações transformadoras da realidade. 
Epistemologicamente, é uma alternativa contra hegemônica de produzir conhecimento científico que circula para além dos espaços acadêmicos. É uma superação da dicotomia entre teoria e prática, pois as fontes da produção coletiva de conhecimento não partem apenas da conciliação entre as necessidades dos sujeitos da pesquisa e dos pesquisadores (tendo estes últimos a prioridade); o conhecimento é produzido sobre e a partir dos recortes, das escolhas selecionadas para serem sistematizadas pelos sujeitos e, prioritariamente, das aprendizagens que essa sistematização propiciou para todos os envolvidos no processo. Assim, ao sistematizar experiências "consideramos a teoria e a prática na sua unidade, em que ambas se nutrem da prática sócio histórica e da ação transformadora, potencializadoras dos processos de lutas pela dignidade humana" (PAULO, 2019, p. 35).

É essa unidade que encontramos na obra Memórias e trajetórias: sistematização de experiências de educação popular e movimentos sociais, fruto da dissertação de mestrado de Fernanda Paulo - educadora popular, Doutora em Educação pela Unisinos/RS, professora e pesquisadora -, a partir da pesquisa realizada junto à Associação de Educadores Populares de Porto Alegre/AEPPA e ao Movimento de Educação Popular/MEP. Lançada em formato de livro no ano de 2019, a obra representa uma unidade a qual encontra lugar fecundo nas experiências de educação popular, que, como ressalta Carlos Rodrigues Brandão no prefácio, constitui-se em um movimento de construção de um novo projeto de sociedade, sendo uma ação efetiva de resistência frente à mercantilização da educação e ao neoliberalismo.

Para Brandão, o trabalho de Paulo enquanto educadora popular, militante e pesquisadora tem um duplo mérito e dupla função pedagógica: primeiro, o trabalho praticado enquanto modalidade de educação popular, na formação de educadores e educadoras; e, segundo, no exercício da sistematização e síntese em forma de livro, como um depoimento e registro do que se pode praticar como e por meio da educação popular (BRANDÃO, 2019).

Este duplo mérito, que compreende a dimensão da unidade, também é percebido pela própria autora ao, por exemplo, se identificar como educadora popular participante da AEPPA e ao salientar que a obra é um compromisso político e pedagógico assumido junto à Associação desde 2010. Político, pois, como sinaliza a autora, há uma invisibilização intencional do trabalho educativo e dos(as) educadores(as) populares, por isso, "compartilhar as minhas experiências de pesquisa é, igualmente, dividi-las com centenas de educadores e educadoras populares[...]" (PAULO, 2019, p. 21); pedagógico, pois a precarização do trabalho incide sobre os processos de formação e de identidade desses educadores e educadoras.

Tendo em vista esse compromisso, ela propõe apresentar 
Uma análise do trabalho desenvolvido pelos educadores e educadoras populares de Porto Alegre, inseridos nas associações comunitárias de bairro, as quais estão conveniadas (Regime de Colaboração) com a Prefeitura Municipal de Porto Alegre, no que concerne a execução das políticas da educação e da assistência social. [...] O estudo resgatou as lutas populares dessa cidade, desde as políticas destinadas às crianças e adolescentes das comunidades populares, associando-as à história dos Movimentos Sociais Populares e da Educação Popular no Brasil buscando conectálas a AEPPA, bem como aos sujeitos que dela participam. (PAULO, 2019, p.19).

Existem muitas formas de sistematizar experiências. Oscar Jara (2010) mostra que não existe um mapa, uma receita que possa ser seguida para garantir a validade e a qualidade dessa experiência teórico-prática. O que existe, segundo ele, são condições necessárias ao exercício desse processo educativo que se baseia na vivência de experiências. Descobrir e explicitar o que há de essencialmente pedagógico, as aprendizagens construídas, é elemento-chave para a análise e a interpretação crítica do que é sistematizado. Ou seja, é preciso conhecer o passado, recuperar a história dos processos vividos e reinterpretá-la criticamente.

Paulo inicia esse processo a partir de sua própria história. No entrecruzamento de suas experiências pessoais e sua militância junto à AEPPA e ao MEP, a autora inicia o primeiro capítulo apresentando um breve registro de sua trajetória desde 1997, quando fazia magistério e teve que interromper os estudos para trabalhar; até tornar-se uma educadora popular doutora, em 2018. Na segunda parte do capítulo, é apresentada a Associação de Educadores Populares de Porto Alegre. Em sua contextualização, a autora afirma que no município existem mais de 2.400 educadores(as) que atuam em diferentes projetos sociais de cunho popular, mas que nem todos se identificam como tal. "Mediante minha participação na AEPPA, percebi que não era apenas uma professora ou educadora social. Essas titulações definiam minha ocupação profissional e não minha militância" (PAULO, 2019. p. 28).

Foi na AEPPA, portanto, que ela, como tantas outras e tantos outros, tornaram-se educadoras(es) populares. Foi ali que constituíram uma identidade comum, por meio de processos formativos. É a partir da formação desta identidade que as lutas pela formação dos(as)educadores(as) populares de Porto Alegre são narradas no segundo capítulo, que apresenta a trajetória da AEPPA desde a sua criação, na década de 1990, até os dias atuais, por meio de documentos como atas, registros internos, fotografias e notícias de jornais locais.

Para a pesquisadora-militante, a Associação caracteriza-se como um local de lutas e conquistas (por espaços educativos, por formação acadêmica, pelo desenvolvimento e garantia de políticas públicas, pela profissionalização etc.) a partir da prática da Educação Popular. Paulo narra, ainda, a trajetória e as experiências das educadoras e dos educadores populares em reuniões, seminários e em plenárias locais. Vale destacar que o envolvimento e o 
comprometimento desses trabalhadores contribuíram para muitas conquistas da AEPPA, como curso superior em Pedagogia e pós-graduação, nos anos 2000.

No terceiro capítulo, a autora apresenta o corpo teórico que estrutura suas reflexões a partir de uma ampla discussão acerca da Educação Popular e dos Movimentos Sociais em perspectiva histórica e contexto nacional. Vale destacar a ampla revisão da obra de Paulo Freire, autor-chave para as análises. A partir dele, os(as) educadores(as) são compreendidos como intelectuais revolucionários, ou seja, sujeitos políticos comprometidos com a própria classe na luta pela educação libertadora, problematizadora e humanista (PAULO, 2019). No entanto, como ressalta a autora, “[...] podemos observar que na realidade concreta dos cursos de formação de educadores(as), poucos são os que objetivam o empoderamento das classes populares e que possuem uma proposta interdisciplinar articulada às histórias das lutas populares" (PAULO, 2019, p. 161).

Ao discutir, no quarto capítulo, a formação dos(as) educadores(as) populares no contexto da AEPPA, é dada ênfase aos diferentes contextos nos quais estão inseridos, às diferentes práticas de educação e diferentes legislações que regulam o trabalho dos associados. No capítulo seguinte, o trabalho dos educadores(as) é apresentado e contextualizado histórica e geograficamente em Porto Alegre, a partir das lutas dos movimentos populares e das políticas de convênio estabelecidas entre o município e as instituições comunitárias e/ou associações.

Em suas considerações, a autora destaca a dimensão pessoal e coletiva da pesquisa, enfatizando que o estudo contribuiu tanto para a sua formação pessoal enquanto educadora da AEPPA, pois pode refletir a analisar a própria trajetória como educadora popular, quanto para que a AEPPA, enquanto coletivo, pudesse compreender suas potencialidades e fragilidades. Dentre estas, destaca: 1) a falta de espaço físico próprio; 2) elevada taxa de contribuição para associados; 3) dúvidas quanto a benefícios, como bolsas de estudos, para não associados; 4) possibilidade de formação de educadores(as) em cursos conveniados com rede de associações; 5) formação política para a cidade.

De forma geral, cabe destacar a reflexão acerca da produção bibliográfica sobre educadores(as) populares(as). Conforme Paulo (2019), embora encontrar produções acadêmicas que usem como referência bibliográfica autores e obras que tratem da temática (como Paulo Freire, Felipe Aranha, Carlos Rodrigues Brandão, Balduíno Andreola e Vera Barreto, dentre outros(as)) não seja uma tarefa complicada, encontrar produções que tratem das experiências de educares(as) mostrou-se um trabalho complexo e, praticamente, infrutífero.

O reduzido número de artigos e a não localização de livros a respeito da formação desses sujeitos, diz Paulo (2019, p. 149), levou-a a supor que "a falta de formação, valorização e 
reconhecimento por parte da universidade a respeito das experiências dos educares(as) populares, pode ter sido um dos motivos para a redução de produções bibliográficas dessa tipologia". Outra hipótese apresentada é de que as produções não reconhecem os sujeitos como educadores(as) populares ou eles não se reconhecem como tal e, portanto, não são nomeados assim, inviabilizando a busca. Apresenta, desse modo, um estudo sobre as pesquisas e as experiências de formação de educadores(as) na $\mathrm{EP}$, discutindo se é relevante ou não a reformulação dos cursos de formação de educadores(as).

Outro ponto relevante da obra é o detalhamento metodológico, que permite não apenas compreender a pesquisa em si, mas compreender os pressupostos da Pesquisa Participante em sua dimensão teórico-metodológica. Mais do que uma síntese do percurso realizado por Paulo (2019), a obra é, nesse sentido, um fecundo material de estudo para aqueles que desejam ingressar ou adensar no campo da Educação Popular e das metodologias participativas na América Latina.

\section{Referências}

BRANDÃO, Carlos R. Prefácio: memórias, trajetórias, lutas e esperanças. In: PAULO, Fernanda dos Santos. Memórias e trajetórias: sistematização de experiências de educação popular e movimentos sociais. São Paulo: Diálogo Freireano, 2019, p. 11-21.

JARA, Oscar. Para sistematizar experiências. Ministério do Meio Ambiente: Brasília, 2010. 